\title{
Geochemical cycling of silver in marine sediments along an offshore transect
}

\author{
Jennifer L. Morford ${ }^{a^{*}}$ \\ Linda H. Kalnejais ${ }^{b \dagger}$ \\ Peter Helman $^{\mathrm{a}}$ \\ Gloria Yen ${ }^{\mathrm{a}}$ \\ Melissa Reinard $^{\mathrm{a}}$ \\ ${ }^{\mathrm{a}}$ Franklin \& Marshall College, Department of Chemistry, \\ P. O. Box 3003, Lancaster, PA USA 17604-3003 \\ ${ }^{\mathrm{b}}$ Woods Hole Oceanographic Institution, Marine Chemistry and Geochemistry \\ Department, Woods Hole, MA USA 02543 \\ ${ }^{\dagger}$ Present address: Department of Earth and Planetary Science, University of California, \\ Berkley, CA USA 94720
}

*Corresponding author: phone 717-358-4590; fax 717-291-4343;

email: jennifer.morford@fandm.edu

Submitted to Marine Chemistry - March 14, 2007

Resubmitted to Marine Chemistry - October 29, 2007

Resubmitted to Marine Chemistry - February 8, 2008 


\begin{abstract}
Although there have been many surface water and water column silver (Ag) analyses in the ocean, the absence of high resolution pore water and solid phase Ag profiles has hampered our understanding of its oceanic geochemical cycling. This manuscript presents pore water and solid phase profiles of Ag along an offshore transect in the northeast Pacific off the coasts of Washington/Oregon states, U.S.A.. Pore water Ag concentrations are uniformly low $\left(<0.3 \mathrm{nmol} \mathrm{kg}^{-1}\right)$ in profiles from sediments that have low bottom water oxygen concentrations, have shallow oxygen penetration depths $\left(\mathrm{O}_{2, \text { pen }}<1 \mathrm{~cm}\right)$ and underlie short water columns $(<500 \mathrm{~m}$ water depth $)$. The solid phase Ag concentrations at these sites are also low $\left(<1 \mu \mathrm{mol} \mathrm{kg}^{-1}\right)$. This is in contrast to sediments from intermediate water depths $(\sim 2000 \mathrm{~m})$ that have similar oxygen penetration depths $\left(\mathrm{O}_{2, \text { pen }}<1 \mathrm{~cm}\right)$, but have elevated pore water Ag concentrations $(0.7$ nmol kg${ }^{-1}$ ) at the sediment-water interface and higher solid phase Ag concentrations (4$8 \mu \mathrm{mol} \mathrm{kg}^{-1}$ ). At sites from $\sim 3000-4000 \mathrm{~m}$ water depth, where $\mathrm{O}_{2, \text { pen }}>1 \mathrm{~cm}$, pore water Ag concentrations reach extremely high concentrations in the top $5 \mathrm{~cm}\left(8-24 \mathrm{nmol} \mathrm{kg}^{-1}\right)$. High concentrations in pore waters provide evidence for a flux of Ag from ocean sediments, but the more oxidizing nature of these sediments precludes appreciable solid phase Ag accumulation in the top $30 \mathrm{~cm}\left(<2 \mu \mathrm{mol} \mathrm{kg}^{-1}\right)$. The accumulation of $\mathrm{Ag}$ in sediments is not simply dependent on redox conditions; more oxidizing sediments do not accumulate solid phase Ag, and neither do more reducing sediments from shallow water depths. Only a sufficiently long water column will result in additional delivery of Ag to
\end{abstract}


sediments by scavenging onto settling particles, and result in Ag accumulation in sediments where $\mathrm{O}_{2, \text { pen }}<1 \mathrm{~cm}$.

Although upward Ag fluxes from sediments underlying shorter water columns are small (0.02-0.07 nmol cm $\left.\mathrm{cm}^{-2}\right)$, calculated fluxes increase for sediments underlying longer water columns and are largest for the more oxidizing sediments $\left(2-5 \mathrm{nmol} \mathrm{cm} \mathrm{y}^{-2}\right.$ $\left.{ }^{1}\right)$. Calculated fluxes of pore water Ag to the solid phase at these more oxidizing stations are inconsistent with measured solid phase Ag concentrations and suggest that the pore water profiles represent non-steady state conditions. Clearly, the early diagenesis of Ag is a highly dynamic process and more research is required to fully understand Ag cycling in sediments in continental margin locations.

Key Words: silver, rhenium, diagenesis, continental margins, trace metals Regional Index Terms: USA, Washington/Oregon continental margin 


\section{INTRODUCTION}

Previous efforts at understanding silver (Ag) cycling in sediments have largely been driven by its association with various industrial uses (photographic, electronic, electroplating) and subsequent release from wastewater treatment facilities (Sung et al., 1986) into rivers and coastal environments (Sañudo-Wilhelmy and Flegal, 1992; Gobeil et al., 2005). Coastal pore water profiles suggest that Ag is released at the sedimentwater interface during the oxidation of organic matter (Rivera-Duarte and Flegal, 1997). Dissolved Ag concentrations in estuaries are further influenced by the input of river water with significant anthropogenic Ag and can be enhanced by sediment resuspension, which results in the release of colloidal Ag (Wen et al., 1997). Pore water Ag profiles from Long Island Sound and speciation calculations suggest that metal-polysulfide and bisulfide complexes control pore water Ag concentrations under anoxic conditions (Lyons and Fitzgerald, 1983), and elevated pore water Ag concentrations from San Francisco Bay, which has anoxic pore waters, are presumably due to the formation of soluble Ag-sulfide complexes (Rivera-Duarte and Flegal, 1997). Under more oxidizing conditions, pore water Ag concentrations that are greater than bottom water concentrations suggest $\mathrm{Ag}$ release from $\mathrm{Mn}$ and/or Fe (oxyhydr)oxides or oxidation of Fe monosulfides (Lyons and Fitzgerald, 1983; Kalnejais, 2005). The majority of particulate $\mathrm{Ag}$ in the estuarine water column is associated with $\mathrm{Mn}$ and/or Fe sulfide phases, and experimental work suggests that both organic and inorganic sulfides are most likely carrier phases for Ag (Wen et al., 1997).

Examination of oceanic Ag cycling has focused on surface waters and the water column (e.g., Martin et al., 1983), but sediment data are limited. Concentrations of Ag in 
surface waters are controlled by riverine, atmospheric and anthropogenic inputs (Klein and Mulvey, 1978; Ndung'u et al., 2001; Zhang et al., 2001; Ranville and Flegal, 2005). As with many other elements, Ag displays nutrient-type behavior (Broecker and Peng, 1982; Nozaki, 1997) with surface depletion and increasing concentrations with depth (Martin et al., 1983; Flegal et al., 1995; Ndung'u et al., 2001; Zhang et al., 2001; Ranville and Flegal, 2005). Diatoms and dinoflagellate production appears to remove Ag from surface waters by either adsorption to cell surfaces or incorporation during growth (Fisher and Wente, 1993). Ag that has been taken up by organisms and sequestered in their hard parts, particularly siliceous diatom tests, is then efficiently transported to deeper waters where it is released during remineralization (Ndung'u et al., 2001).

Surface sediments off the coast of Peru have elevated solid phase Ag concentrations and suggest that Ag accumulation in sediments is most likely from input of diatomaceous matter (Böning et al., 2004). Sediment Ag enrichments underlying longer water columns may be indicative of Ag being scavenged from seawater by settling particles resulting in a greater flux of Ag to the sediment-water interface (McKay and Pedersen, 2002). For example, surface sediments off the coast of Chile have Ag concentrations that increase with water depth (Böning et al., 2005), which may be indicative of Ag being scavenged from seawater by settling particles. Further diffusion of Ag into pore waters and greater solid phase Ag accumulation could be due to higher bottom water Ag concentrations produced from the progressive release of Ag via the degradation of settling biogenic material (Böning et al., 2005). Therefore, unlike other conservative redox-sensitive trace metals such as rhenium (Re), uranium (U) and molybdenum (Mo) that respond to the extent of reducing conditions (e.g., Colodner et al., 
1993; Crusius et al., 1996; Morford and Emerson, 1999; Nameroff et al., 2002; Morford et al., 2005, 2007; McManus et al., 2006), solid phase Ag concentrations may also be responding to water depth and higher bottom water Ag concentrations, which increase $\mathrm{Ag}$ diffusion into sediments.

Diagenetic remobilization of Ag from sediments to overlying waters could potentially be an important source of Ag, both in coastal (Rivera-Duarte and Flegal, 1997; Kalnejais, 2005) and ocean (Ranville and Flegal, 2005) areas. The primary goal of this paper is to characterize the early diagenetic behavior of $\mathrm{Ag}$ in sediments, using both pore water and solid phase Ag profiles, along an offshore transect that spans a range in bottom water oxygen concentration and organic carbon flux to the sediment to discern the controls on Ag accumulation in sediments and the potential for a sedimentary Ag source to deep ocean waters.

\subsection{Study Site}

Cruise TTN-131 (July-August, 2001) followed and extended a transect previously described in Hedges et al. (1999) and Devol and Harnett (2001). The transect was primarily along $47^{\circ} \mathrm{N}$ from the continental shelf off of Washington/Oregon states (U.S.A.) to the west side of the Juan de Fuca Ridge (Figure 1; Stump and Emerson, 2001). Carbon rain rates have been shown to be higher closer to the continent, approximately $5 \mathrm{mmol} \mathrm{m}^{-2} \mathrm{~d}^{-1}$ at $440 \mathrm{~m}$ water depth, and decrease dramatically with increasing water depths (approximately $1-2 \mathrm{mmol} \mathrm{m}^{-2} \mathrm{~d}^{-1}$ at $620 \mathrm{~m}$ water depth; Devol and Hartnett, 2001). The water column dissolved oxygen distribution shows an oxygen minimum extending from approximately 700-1100 m water depth (Hartnett and Devol, 
2003; Devol and Hartnett, 2001); however, oxygen concentrations are always greater than $20 \mu \mathrm{M}$ and denitrification in the water column is not an important process (Hartnett et al., 1998). Sampling along this transect resulted in a range of overlying productivities, carbon fluxes to the sediment-water interface, and sediment oxygen penetration depths (Tables 1 and 2). Stations 1, 2, 3b and 4 have oxygen penetration depths that are less than one centimeter $\left(\mathrm{O}_{2, \text { pen }}<1 \mathrm{~cm}\right)$, while stations $5,6,7$ and 8 have oxygen penetration depths that extend from $1.4 \mathrm{~cm}$ to $5 \mathrm{~cm}$.

\section{METHODS AND ANALYTICAL PROCEDURES}

\subsection{Sampling Methods}

Prior to the cruise, 4-mL HDPE bottles for storing pore waters were cleaned by filling with $2 \mathrm{M} \mathrm{HCl}$ for four days at $60^{\circ} \mathrm{C}$, rinsing with $18 \mathrm{M} \Omega$ MilliQ (MQ) water, and drying in a laminar flow hood. Concentrated nitric acid that was used to acidify pore water samples was double-distilled in a quartz still at the University of Washington. All syringes and filters were cleaned with $2 \mathrm{M} \mathrm{HCl}$, rinsed and dried in a laminar flow hood.

Sediment cores (30-60 cm in length) with clearly defined sediment-water interfaces and overlying waters that were clear of resuspended sediment upon recovery were collected using a multi-corer. Cores were immediately capped with plasticwrapped rubber stoppers and moved to a $4^{\circ} \mathrm{C}$ room. All core processing occurred at $4^{\circ} \mathrm{C}$ in a refrigerated van while at sea. The overlying waters were sampled and the cores were then sectioned in a nitrogen-filled glove bag. Samples for metal analyses were obtained by filling scintillation and centrifuge vials of known volume. The first six samples were from intervals of $\sim 0.35 \mathrm{~cm}$ and samples $7-12$ consumed depth intervals of $\sim 0.6 \mathrm{~cm}$ each. 
This sampling method required sampling across the entire surface including sediment against the core liner; however, sharp metal profiles in the top 12 samples suggest minimal profile smearing (Morford et al., 2005). Sediment sampling continued at $1 \mathrm{~cm}$ or $2 \mathrm{~cm}$ intervals to the bottom of each core.

Sediments were centrifuged and pore waters were filtered in a nitrogen-filled glove bag, using nitrogen-flushed syringes and $0.45 \mu \mathrm{m}$ filters. Pore water samples were acidified at sea with $75 \mu \mathrm{L}$ of concentrated double-distilled nitric acid.

\subsection{Analytical Procedures - Pore Water and Solid Phase}

Pore water Ag concentrations were determined using a Co-APDC (cobaltammonium 1-pyrrolidine-carbodithioic acid) co-precipitation method similar to the method described in Boyle and Edmond (1977) and described in detail in Kalnejais (2005). The cobalt (II) solution was purified using an AG 1-X8 resin, the ammonium hydroxide solution was purified by headspace distillation, and the ammonium 1pyrrolidine-carbodithioic acid (APDC) solution was purified by extraction with

chloroform. Briefly, pore water samples were spiked with a ${ }^{109} \mathrm{Ag}$ isotope spike (Oak Ridge National Laboratory) and equilibrated for 48 hours. Silver was then coprecipitated with cobalt ammonium pyrrolidinedithiocarbamate through the addition of cobalt (II), ammonium hydroxide, and 2\% APDC solutions to the sample. The resulting precipitate was digested with concentrated nitric acid (Fisher Optima grade) and analyzed on the Element or Element2 (Finnigan) high resolution inductively coupled plasma mass spectrometer (ICP-MS) at the Woods Hole Oceanographic Institution. 
Literature has shown that measured Ag concentrations in non-UV exposed acidified ocean samples years after collection appear to underestimate the Ag concentration by $22 \pm 11 \%$ compared to UV-treated samples, presumably due to Ag adsorption to precipitated humic acids (Ndung'u et al., 2006). Samples in this study were not exposed to ultraviolet (UV) light prior to the Co-APDC co-precipitation method, but were stored at $\mathrm{pH}<1$ with nitric acid, which should have resulted in digestion of refractory organics (Rivera-Duarte and Flegal, 1996). Assuming that the Ag isotope spike equilibrated with the Ag in the samples analyzed in the work presented here, then incomplete Ag extraction would not be problematic as long as sufficient Ag was recovered for analysis. If the organic ligands were too strong or kinetically inert (i.e., Kogut and Voelker, 2003), it could be possible that the Ag isotope spike would not completely equilibrate with the entire Ag pool and the extracted Ag concentration would be underestimated. However, earlier tests comparing coastal pore waters that were UV treated and untreated suggested that there was no statistical difference, and implied that either the Co-APDC extraction method was strong enough to extract Ag for analysis or the Ag isotope spike was able to equilibrate with the entire Ag pool (Kalnejais, 2005).

Solid phase Ag concentrations were determined using an aqua regia leach method. The concentrations are denoted as non-lithogenic Ag concentrations because hydrofluoric acid was not used during the digestion. Aqua regia alone does not dissolve silicates (Chao and Sanzolone, 1992), so the Ag within the matrix of silicate minerals will not be liberated by the digestion technique used. Approximately $1 \mathrm{~g}$ of dried sediment was combined with freshly prepared aqua regia in a closed Teflon vessel (Savillex) and refluxed on a hotplate for approximately six hours, after which time the aqua regia was 
evaporated and several aliquots of $2 \mathrm{M} \mathrm{HCl}$ were added and evaporated. A final aliquot of $0.1 \mathrm{M} \mathrm{HCl}$ was added, and the sample was filtered using an acid-cleaned $0.45 \mu \mathrm{m}$ filter (Whatman). The Ag in the sample was preconcentrated, following a modified version of the method of Yang and Sturgeon (2002), using Dowex AG1-X8 resin (BIO-RAD, chloride form, 100-200 mesh). All samples were spiked with scandium, and silver/scandium ratios were measured to correct for any instrument variability or drift. Leached Ag concentrations were quantified by calibration curve at Franklin \& Marshall College using a Spectro Ciros CCD inductively coupled plasma atomic emission spectrometer (ICP-AES) using a wavelength of $328.068 \mathrm{~nm}$. Several solid phase samples were measured for total Ag following complete dissolution using a modified version of the method outlined in Murray and Leinen (1993) and Morford and Emerson (1999). These samples were quantified using isotope dilution $\left({ }^{109} \mathrm{Ag}\right)$ and the ICP-MS at the Woods Hole Oceanographic Institution.

\section{RESULTS AND DISCUSSION}

\subsection{Method Results - Accuracy and Precision}

The accuracy of the pore water co-precipitation method was determined by replicate analyses of CASS-4 (Nearshore Seawater Reference Material, National Research Council Canada). Although CASS-4 is not certified for Ag, there have been several determinations of Ag concentrations in the literature (Table 3). The average Ag concentrations measured during this research are consistent with Yang and Sturgeon (2002) and Ndung'u et al. (2001), but are lower than the average value in Ndung'u et al. (2006). The relative standard deviation is $\leq 17 \%$ for replicate measurements of CASS -4 . 
When a sample of CASS -4 was spiked so that the expected concentration was $\sim 530$ pmol $\mathrm{kg}^{-1}$, the efficiency of the extraction was $105 \pm 5 \%(\mathrm{n}=8)$. Analysis of pore water samples for Ag were completed in 2002 (station 3b), 2004 (station 2), and 2006 (stations 5-8). The pore water profiles from stations 2 and 3b, which are from similar water depths and redox conditions in sediments, are comparable and suggest negligible storage artifacts over the time period between analyses (Table 4). Replicates of station 4 pore water samples that were done in 2004 and repeated in 2006 suggest little change in concentration (Table 3). The precision of replicate pore water samples analyzed two years apart using the preconcentration method is $\leq 14 \%$.

Pore water manganese $(\mathrm{Mn})$ is within the $95 \%$ confidence interval of the known concentration for CASS -4 and the precision was $\leq 20 \%$ (Morford et al., 2005). Duplicate samples from station $3 \mathrm{~b}$, taken from $0.9 \mathrm{~cm}$ below the sediment-water interface, were measured to determine the precision for iron (Fe) which is $<5 \%$ (Morford et al., 2005).

The leached solid phase concentrations overlap with the certified concentrations for marine sediment standard reference materials PACS-2 and MESS-3 (Marine Sediment Reference Material, National Research Council Canada) at the 95\% confidence level (Table 5), which is consistent with previous results using similar extraction methods (e.g., Rivera-Duarte and Flegal, 1997). Reproducibility was $\leq 7 \%$ for replicate analysis of PACS-2 and MESS-3 using the leach method. Leached Ag concentrations in sample replicates had slightly lower precision, but were still typically $\leq 9 \%$ except for a pair of duplicates that had $14 \%$ and $16 \%$ relative standard deviations (Table 6). The total dissolution method resulted in Ag concentrations that were $15-20 \%$ higher than the 
average published $\mathrm{Ag}$ concentration and the precision was $\leq 5 \%$ for the MESS-3 standard, which was repeatedly analyzed (Table 5).

The reproducibility of the Fe and Mn solid phase analyses were determined by duplicate analyses. Precisions are $\leq 5 \%$ for Fe and $\leq 8 \%$ for Mn for solid phase sample analyses (Morford et al., 2005).

\subsection{Iron and Manganese}

The Fe and Mn pore water and solid phase profiles have already been discussed in detail (Morford et al., 2005); however, a brief discussion of these data provide the necessary context with respect to redox conditions in the sediments within which to discuss the Ag results.

Pore water Fe concentrations are elevated below the first centimeter at stations 2 and $3 \mathrm{~b}$ and below about $5 \mathrm{~cm}$ at station 4 (Figure 2). Fe concentrations at all other stations are low throughout their respective profiles. Surface solid phase Fe enrichment at station 2 is consistent with remobilization from deeper sediments and precipitation at the sediment-water interface. Therefore, Fe does not appear to significantly diffuse to overlying waters, implying that Fe cycling is restricted to sediments and does not extend to overlying waters, which is consistent with the results of Thamdrup et al. (1994).

Mn is below $8 \mu \mathrm{M}$ in all pore waters from stations $2,3 \mathrm{~b}$ and 4 , where oxygen penetrates less than $1 \mathrm{~cm}$ below the sediment-water interface. Mn oxide reduction appears to be occurring very close to the sediment-water interface where $\mathrm{Mn}^{2+}$ can diffuse to the overlying waters (Figure 2). The solid phase profiles from stations 2 and 4 are consistent with this interpretation, showing Mn depletion relative to detrital estimates 
(Figure 2). High concentrations of pore water $\mathrm{Mn}$ are seen below $\sim 5$ to $10 \mathrm{~cm}$ depth in cores from stations 5, 6 and 7 (Figure 2). Iron oxyhydroxide reduction is probably occurring at these stations, but oxygen, nitrate, or Mn oxides (Myers and Nealson, 1988)

may be used to oxidize $\mathrm{Fe}^{2+}$ thereby removing $\mathrm{Fe}^{2+}$ from pore waters and results in measurable Mn but low Fe in pore waters. Station 6, which is close to the Juan de Fuca Ridge crest, is probably influenced by hydrothermal activity resulting in high pore water Mn concentrations and both Mn and Fe solid phase enrichment (Figure 2, see discussion in Morford et al., 2005). Only at station 8 are both Mn and Fe absent from upper pore waters; however, hydrothermally influenced solid phase Mn enrichment is apparent throughout the top $28 \mathrm{~cm}$ of this core (Figure 2).

The compilation of $\mathrm{Mn}$ and Fe data from this transect describes the overall redox conditions in the sediments and the influence of nearby hydrothermal activity. The more reducing sediments from stations $2,3 \mathrm{~b}$ and 4 are easily identifiable by their shallow oxygen penetration (Table 1) and increasing pore water Fe concentrations within the top $5 \mathrm{~cm}$ below the sediment-water interface. The more oxidizing conditions at stations 5,6 and 7 are evident from their deeper oxygen penetration, lack of pore water Fe and presence of pore water Mn. The most oxic sediments are found at station 8 , where the oxygen penetration depth is the deepest and there is an absence of both Fe and $\mathrm{Mn}$ in pore waters.

\subsection{Silver}

\subsubsection{Solid phase non-lithogenic Ag concentrations}


To a first approximation, the solid phase metal concentration in sediments is the sum of three phases: the refractory phase (metals bound within silicate mineral lattices), the biogenic phase (metals bound to organic matter, delivered to the sediments and possibly released during organic matter degradation), and the authigenic phase (metals incorporated after sediment deposition due to redox conditions). The combination of acids used during the leach method extracts Fe and Mn oxides, carbonates, sulfides, selenides and some organic matter (Chao and Sanzolone, 1992). The Ag concentration determined using the leach method approximates the non-lithogenic Ag concentration, which includes both the authigenic and biogenic fractions; however, the absence of hydrofluoric acid in the method precludes the complete extraction of refractory Ag from silicates. The difference between the measured Ag concentrations using the leach method and the total dissolution method provides an estimate of the refractory Ag component in the solid phase. The average Ag concentration measured in a selection of samples that were totally dissolved from stations $1,2,4,5,6$ and 7 is $0.4 \pm 0.3 \mu \mathrm{mol} \mathrm{kg}{ }^{-1}$ $(n=13)$ higher than the Ag concentrations measured in the same samples analyzed following the leach method (Table 6). This average refractory Ag concentration that is not extracted during the leach method is indistinguishable from literature estimates for detrital Ag concentrations (Table 7).

Station $3 \mathrm{~b}$ solid phase Ag concentrations from totally dissolved samples were greater than those samples that were leached by $1.4 \pm 0.3 \mu \mathrm{mol} \mathrm{kg}^{-1}(\mathrm{n}=2)$. The higher refractory Ag concentration at this location is possibly due to the closer proximity of station $3 \mathrm{~b}$ to the Columbia River (Figure 1). Limited analyses of river particles from other locations have Ag concentrations that are 10-800 times larger than detrital 
concentrations (Martin and Maybeck, 1979; Table 7), due to either weathering of source rocks with higher Ag concentrations or anthropogenic input. Two samples of suspended river particles collected from the Columbia River and measured using the total dissolution method are consistent with these possibilities. The average Ag concentration in the suspended particulate material from the Columbia River is $12 \pm 5 \mu \mathrm{mol} \mathrm{kg}^{-1}$, which is greater than any of the solid phase Ag concentrations measured from the Washington/Oregon margin (Table 6). It is possible that the Columbia River adds Ag enriched material to Stations 1,2 and 4, but this is unlikely given that the average refractory concentration at these stations $\left(0.5 \pm 0.2 \mu \mathrm{mol} \mathrm{kg}{ }^{-1}, \mathrm{n}=7\right)$ is similar to distal stations (e.g., 5, 6 and 7; $0.4 \pm 0.3 \mu \mathrm{mol} \mathrm{kg}^{-1} ; \mathrm{n}=6$ ). We therefore assume little additional Ag input at stations 1, 2 and 4, presumably due to their locations farther from the Columbia River. The higher and perhaps variable refractory Ag concentration present at station $3 \mathrm{~b}$ complicates our interpretation of its solid phase profile, as the site is obviously impacted by the Columbia River.

\subsubsection{Pore water and solid phase Ag profiles}

Pore water Ag concentrations are uniformly low $\left(<0.3 \mathrm{nmol} \mathrm{kg}^{-1}\right.$, Figure 3$)$ in the profile from station 2 , which has a low bottom water oxygen concentration and a shallow oxygen penetration depth $\left(\mathrm{O}_{2, \text { pen }}<1 \mathrm{~cm}\right)$. The elevated pore water $\mathrm{Ag}$ concentration at the sediment-water interface at station 4 is presumably due to release of Ag during organic matter degradation, forming either aqueous Ag chloride (Rivera-Duarte and Flegal, 1997) or sulfide (Rozan and Luther, 2002; Adams and Kramer, 1999) complexes. 
Decreasing pore water Ag concentrations with depth at stations $3 \mathrm{~b}$ and 4 suggest removal from pore water to the solid phase. Solid phase Ag concentrations are highest in the profile from station 4 (Figure 4), which is the location from the deepest water depth with $\mathrm{O}_{2, \text { pen }}<1 \mathrm{~cm}$.

Pore water Ag profiles from stations 5, 6, 7 and 8, which lie at greater water depths and are from more oxidizing locations with $\mathrm{O}_{2, \text { pen }}>1 \mathrm{~cm}$, are dramatically different than shallow water stations. Surface concentrations are low and then increase with depth (Figure 3). The removal of Ag from pore waters near the sediment-water interface may be due to a flux of $\mathrm{Ag}$ to overlying waters or $\mathrm{Ag}$ adsorption onto freshly precipitating oxides, although there is limited evidence of Ag cycling with either Mn and/or Fe (oxyhydr)oxides since stations with extremely large solid phase Mn and/or Fe enrichments (stations 6 and 8) have low concentrations of solid phase Ag (Figure 4). At the more oxidizing locations, pore water $\mathrm{Ag}$ reaches extremely high concentrations in the top $5 \mathrm{~cm}\left(\sim 24 \mathrm{nmol} \mathrm{kg}^{-1}\right.$ at station 7 and $8-13 \mathrm{nmol} \mathrm{kg}^{-1}$ at stations 5,6 and 8$)$. These high concentrations could reflect the oxidation of $\mathrm{Ag}$-rich biogenic material or dissolution of $\mathrm{Ag}$-bearing mineral phase(s). Unexpectedly, these pore water concentrations are comparable to those measured in $\mathrm{Ag}$-contaminated sediments from areas with large anthropogenic inputs, such as San Francisco Bay (0.007 to $4.6 \mathrm{nM}$; Rivera-Duarte and Flegal, 1997). However, sediments considered representative of natural conditions within Long Island Sound have also been found to contain high pore water $\mathrm{Ag}(<2$ to $9 \mathrm{nM})$, which has been attributed to the reduction of $\mathrm{Mn}$ and/or Fe (oxyhydr)oxides, the oxidation of Fe monosulfides or the release of Ag during the degradation of organic matter (Lyons and Fitzgerald, 1983). Low pore water Ag 
concentrations deeper than $\sim 8 \mathrm{~cm}$ are indicative of removal to the solid phase, although solid phase Ag concentrations are low for stations 5-8 except for the deepest sample from station 5, suggesting these sites may not be at steady state (see later discussion).

\subsubsection{Controls on Ag cycling in marine sediments}

In the simplest interpretation, the burial of $\mathrm{Ag}$ in the solid phase is bound by two main controls: the flux of Ag to sediments and the conditions in the sediments that may or may not be conducive for authigenic Ag accumulation. Most of the particulate Ag flux likely originates in surface waters via $\mathrm{Ag}$ association with phytoplankton (Fisher and Wente, 1993) and settles to the sediments along with diatomaceous input (Friedl and Pedersen, 1998; Böning et al., 2004), but some Ag may also be scavenged from seawater by settling organic particles (McKay and Pedersen, 2002). Overlying productivity and carbon flux to sediments, which are thought to supply Ag to the sediments, are greatest for stations 1 and 2 (Table 2). Low pore water and solid phase Ag concentrations at stations 1 and 2 suggest that the short distance traveled by particles results in limited $\mathrm{Ag}$ scavenging and therefore limited $\mathrm{Ag}$ delivery to or accumulation in sediments consistent with the hypothesis of McKay and Pedersen (2002). Overlying productivity decreases as the water depth increases to $1000-2000 \mathrm{~m}$, but particles traverse a longer path that results in additional scavenging and a larger flux of $\mathrm{Ag}$ to sediments. Higher pore water concentrations at station 4 are indicative of additional release of Ag to pore waters. The deepest stations, from 2700-3900 m water depth, result in appreciable Ag scavenging by particles, thus a large $\mathrm{Ag}$ flux to sediments, and extremely large pore water $\mathrm{Ag}$ 
concentrations due to oxidation of organic particles and release of incorporated and scavenged Ag.

To a first approximation, it is possible to determine whether the particle Ag flux to sediments is adequate to supply the Ag measured in sediments from deeper water sites. The particle flux at $3000 \mathrm{~m}$ water depth can be estimated using the organic carbon rain rate $\left(0.04 \mathrm{mmol} \mathrm{cm}^{-2} \mathrm{y}^{-1}\right.$; Devol and Hartnett, 2001) and the organic carbon concentration in surface sediments (1.5\%, Hartnett and Devol, 2003). Assuming equilibrium, the particulate $\mathrm{Ag}$ concentration can be approximated using the seawater Ag concentration for $3000 \mathrm{~m}$ water depth $\left(70 \mathrm{pmol} \mathrm{kg}^{-1}\right.$; Kramer, 2006) and the equilibrium distribution coefficient for $\mathrm{Ag}$ in the water column $\left(\mathrm{K}_{\mathrm{d}}=10^{4}-10^{5}\right.$, Smith and Flegal, 1993; SañudoWilhelmy and Flegal, 1992; Wen et al., 1997). The particulate Ag flux can then be calculated using the particulate Ag concentration and the calculated particle flux. For water depths of $3000 \mathrm{~m}$, the settling material has delivered $80-800 \mathrm{nmol} \mathrm{Ag} \mathrm{cm}^{-2}$ over the past 4 kyr. The total inventory of $\mathrm{Ag}$ in sediments, determined by integrating both the pore water and the solid phase profiles down to $\sim 8 \mathrm{~cm}$ ( $\sim 4 \mathrm{kyr})$, is $2-3 \mathrm{nmol} \mathrm{cm}{ }^{-2}$. Even though the range in $\mathrm{K}_{\mathrm{d}}$ used in this calculation is poorly constrained for deep water locations, as it was determined for coastal and estuarine waters, this calculation suggests that particles at equilibrium in the water column can deliver sufficient $\mathrm{Ag}$ to the sediments to supply the measured pore water and solid phase Ag concentrations.

The redox conditions in sediments can be differentiated by the differences in oxygen penetration depth, $\mathrm{Mn}$ and Fe pore water and solid phase profiles (see Section 3.2) and the accumulation of redox-sensitive trace metals, such as $\mathrm{U}$, Re and Mo 
(Morford et al., 2005). U, Re and Mo are conservative redox-sensitive metals that respond to the extent of redox conditions in predictable ways. Generally, when $\mathrm{O}_{2 \text {,pen }} \leq 1$ $\mathrm{cm}$ below the sediment-water interface both Re and $\mathrm{U}$ accumulate authigenically in sediments (Colodner et al., 1993; Crusius et al., 1996; Morford and Emerson, 1999; Nameroff et al., 2002; Morford et al., 2005, 2007; McManus et al., 2006), although accumulation can be compromised in weakly suboxic sediments (McKay et al., 2007). More reducing conditions are typically required for Mo accumulation (Crusius et al., 1996; Morford and Emerson, 1999; Nameroff et al., 2002; Morford et al., 2005, 2007; McManus et al., 2006), and it is possible that Mo removal from pore waters requires the presence of sufficiently rapid sulfate reduction to result in the presence of low concentrations of sulfide, perhaps in microenvironments (Zheng et al., 2000; Morford et al., 2007). Along the transect presented here, $U$ and Re concentrations are clearly enriched in solid phase samples from stations 2 and 4, whereas Mo accumulates authigenically only at station 2 where the sediments are more reducing (Morford et al., 2005). Re concentrations are at detrital levels at stations 6 and 8, while $U$ and Mo concentrations are enriched due to nearby hydrothermal plume processes and their association with solid phase $\mathrm{Mn}$ and/Fe (oxyhydr)oxides (Morford et al., 2005). Solid phase Ag concentrations have been thought to record redox conditions (Crusius and Thomson, 2003), diatom fluxes to sediments (Böning et al., 2004) and water column scavenging (McKay and Pedersen, 2002). The lack of Ag accumulation in the solid phase at stations 1 and 2, which has clear Re and U enrichment, suggests that Ag accumulation is not completely controlled by redox conditions in sediments. Similar results were found in Chilean upwelling sediments where authigenic Ag solid phase 
concentrations increased with water depth; these results were in contrast to solid phase Re concentrations, which decreased with increasing water depth and more oxidizing conditions (Böning et al., 2005). The large solid phase Ag enrichments apparent in sediments from station 4 suggest some redox control for Ag accumulation in sediments, perhaps in conjunction with water column scavenging and an enhanced flux of $\mathrm{Ag}$ to sediments as a result of the longer water column overlying this area (Figure 4). The more oxidizing nature of the sediments at stations 5-8, however, prevents appreciable solid phase Ag accumulation in the top $30 \mathrm{~cm}$.

\subsubsection{Pore water silver fluxes}

The pore water Ag profiles presented here provide evidence for a flux of Ag from sediments to overlying waters. Although bottom water Ag concentrations were not measured as part of this work, Ag concentrations range from 20 to $70 \mathrm{pM}$ at water depths of 400-4000 m off Vancouver Island, British Columbia (Kramer, 2006) and can be used in conjunction with the pore water gradients to calculate diffusive fluxes. The pore water profiles for stations from deeper water depths (stations 4-8) suggest large upward Ag fluxes whereas sediments from shallower water depths show much smaller Ag fluxes to overlying waters. The Ag fluxes from sediments result in upward fluxes at stations 4-8 of $0.2-5 \mathrm{nmol} \mathrm{cm}^{-2} \mathrm{y}^{-1}$ (Table 8). Among sites of similar water depths, there does appear to be a relationship between the magnitude of upward fluxes and redox conditions in the sediments, as larger fluxes are from the more oxidizing sediments with deeper $\mathrm{O}_{2}$,pen depths (stations 5 and 7). This range in Ag fluxes to overlying waters is larger than the Ag flux calculated for a pristine bay near San Francisco Bay $\left(0.012 \mathrm{nmol} \mathrm{cm}^{-2} \mathrm{y}^{-1}\right.$; 
Rivera-Duarte and Flegal, 1997), and could provide a sediment source of Ag to deep ocean waters.

Processes occurring at the sediment-water interface could affect the magnitude of the Ag flux from sediments to overlying waters. It is possible that Ag might be removed at the sediment-water interface at a resolution that is finer than the sampling resolution presented here, so that the calculated upward fluxes do not equate to fluxes to overlying waters. The apparent lack of Ag adsorption to Fe oxyhydroxides (stations 2 and 6, Figure 2) or Mn oxides (stations 6 and 8, Figure 2) would suggest that adsorption to these oxide phases at the sediment-water interface is minimal and would not hinder a flux of Ag to overlying waters, but we cannot rule out adsorption of Ag to other phases in surface sediments that could limit its ability to diffuse to overlying waters. It is also possible that the calculated fluxes are too large because the free ion molecular diffusion coefficient used in the calculation is not appropriate. If $\mathrm{Ag}$ is found in pore water complexed with large organic molecules, then the free ion diffusion coefficient would overestimate the mobility of Ag in pore waters, which is similar to the conclusion formed by Emerson and Huested (1991) to account for the unrealistically large calculated Mo fluxes from sediments to overlying waters.

An additional complication involves the calculated removal flux for Ag from pore waters. Assuming one-dimensional steady state diffusion, the calculated removal flux of Ag from pore waters should equal the solid phase burial flux in sediments (Table 8). The calculated authigenic Ag concentration is within a factor of 15 of the measured authigenic $\mathrm{Ag}$ concentration for the more reducing sediments (stations 2, $3 \mathrm{~b}$ and 4), which is good agreement considering that the sedimentation rates are extrapolated from 
nearby locations. The calculated downward fluxes for the more oxidizing stations predict authigenic concentrations that are 400-10,000 times larger than measured concentrations. The lack of consistency between pore water and solid phase profiles for the more oxidizing stations (i.e., stations 5-8) suggest that the assumption that pore water profiles are at steady state is not correct. These calculations illustrate the potential for a sediment source of Ag into the deep ocean and they highlight the necessity for further data to understand the mechanism for this non-steady state behavior.

\subsubsection{Suitability of Ag and Re as complementary tracers for changes in reducing conditions in sediments}

An appropriate suite of trace metals for discerning the mechanism(s) behind changes in redox conditions in sediments over time remains elusive, although there have been efforts toward correlating $\mathrm{U}$ and Mo accumulation rates with the delivery and burial of organic carbon (McManus et al., 2006). It is possible that solid phase Ag concentrations used in conjunction with Re concentrations might provide a mechanism for discerning changes in organic matter flux to sediments relative to changes in bottom water oxygen concentrations (Friedl and Pedersen, 1998; Crusius and Thomson, 2003).

Re is expected to diffuse from overlying waters to the depth at which it is removed to sediments, which will dictate its solid phase concentration (Crusius et al., 1996; Morford et al., 2007). Re is an ideal tracer for reducing conditions in sediments because its detrital concentrations are extremely low relative to authigenic concentrations, and Re is uncomplicated by adsorption to Mn and/or Fe (oxyhydr)oxides (Morford et al., 2005 and references therein). If $\mathrm{Ag}$ accumulation in sediments depends primarily on the flux of 
organic matter (Flegal et al., 1995; Böning et al., 2004), then sediment Ag concentrations may record changes in organic matter flux. In theory, an enrichment in solid phase Re without a concomitant increase in Ag would suggest an intensification of reducing conditions in sediments and signify that a lowering of bottom water oxygen concentration was responsible for the change in redox conditions and not changes in the flux of organic matter to the sediment. Both Ag and Re can be remobilized upon the exposure of previously anoxic sediment to oxygen (Crusius et al., 2003). There is negligible mobility of authigenic Ag and Re in sediments buried without subsequent oxygen exposure suggesting that high sedimentation environments should preserve the solid phase Ag and Re record (Crusius et al., 2003). Further information regarding Ag geochemical cycling, particularly Ag concentrations in aqueous and solid phase samples from sediments from a range of water depths with a variety of redox conditions, will be necessary before firm conclusions can be formed regarding the potential to separately identify or quantify changes in bottom water oxygen concentration relative to changes in overlying productivity using solid phase concentrations of Ag and Re.

\section{CONCLUSION}

High resolution pore water and sediment profiles of Ag along an offshore transect off the coast of Washington/Oregon states, U.S.A. yield information regarding Ag geochemical cycling in the ocean. The accumulation of Ag in sediments is bound by two main controls: the flux of Ag to sediments and the conditions in the sediments that may or may not be conducive for authigenic accumulation. Pore water Ag concentrations are

uniformly low $\left(<0.3 \mathrm{nmol} \mathrm{kg}^{-1}\right)$ at stations from shallower water depths with more 
reducing sediments (stations 2 and $3 \mathrm{~b}$ ) suggesting that the short distances traveled by particles results in limited Ag scavenging and therefore limited Ag delivery to the sediments. Although overlying productivity decreases with water depth, profiles from deeper stations (2000-4000 m water depth) have higher pore water Ag concentrations suggesting that particles traversing a longer path result in additional scavenged Ag and a larger flux of Ag to sediments, which is subsequently released to pore waters. The largest pore water $\mathrm{Ag}$ concentrations are found in the more oxidizing sediments providing evidence for a flux of Ag from oxidizing sediments to overlying waters and a sediment source of Ag to deep ocean waters. This apparent redox-control on the Ag flux from sediments results in the largest upward fluxes at stations 5 and 7 of $2-5 \mathrm{nmol} \mathrm{cm}^{-2} \mathrm{y}^{-1}$, whereas there are much smaller Ag fluxes to overlying waters from more reducing sediments at shallower water depths. Comparisons between Ag removal fluxes from pore waters and measured solid phase Ag concentrations, however, are not consistent and support the non-steady state nature of the Ag pore water profiles.

The accumulation of solid phase Ag does not appear to be completely controlled by redox conditions in the sediments. There is negligible $\mathrm{Ag}$ accumulation in the more reducing sediments from stations 1 and 2, which have clear authigenic enrichments in $\operatorname{Re}$ and $\mathrm{U}$. The more oxidizing sediments from stations 5, 6, 7 and 8 also lack $\mathrm{Ag}$ enrichment. However, there is Ag enrichment in sediments from station 4, which is the deepest of the stations with $\mathrm{O}_{2 \text {,pen }}<1 \mathrm{~cm}$. The accumulation of $\mathrm{Ag}$ in sediments is not simply dependent on redox conditions, since more oxidizing sediments do not accumulate solid phase Ag, and neither do more reducing sediments from shallow water depths. Only a sufficiently long water column will result in additional delivery of $\mathrm{Ag}$ to 
sediments by scavenging onto settling particles, and result in $\mathrm{Ag}$ accumulation in underlying sediments where $\mathrm{O}_{2, \text { pen }}<1 \mathrm{~cm}$ (i.e., reducing sediments). Clearly, the early diagenesis of $\mathrm{Ag}$ is a highly dynamic process and more research is required to fully understand Ag cycling in sediments in continental margin locations.

\section{Acknowledgements}

JLM thanks Steve Emerson, Al Devol and those involved with TTN 131 for such a productive cruise. The authors would also like to thank Bill Martin (WHOI) for the loan of lab supplies, Lisa Mertzman and Steve Sylvester (F\&M) for help with supplies and the ICP-AES, and Carol Strausser (F\&M) for help with figures. Fred Prahl kindly provided several samples of Columbia River suspended material. Matthew Reuer provided expert guidance to LHK for developing the silver porewater analysis method. JLM acknowledges the ICP-MS expertise provided by Dave Schneider of the WHOI Plasma Facility, and Joanne Goudreau who coordinated the ICP-MS runs for JLM at WHOI for pore water analyses from stations 5-8. Funding for this work was provided to JLM and F\&M students by Research Corporation and the Hackman Summer Research Program at Franklin \& Marshall College. Financial support to JLM and LHK was also provided by the National Science Foundation (OCE-0220892). LHK received additional support from a Hackett Scholarship from the University of Western Australia and the WHOI Academic Programs Office. This manuscript benefited greatly from thorough and thoughtful comments from Ida-Maja Karle, Steve Emerson, Hilairy Hartnett, Associate Editor Rob Sherrell and two anonymous reviewers. 


\section{References}

Adams, N. W. H. and Kramer, J. R., 1999. Determination of silver speciation in wastewater and receiving waters by competitive ligand equilibration/solvent extraction. Environmental Toxicology and Chemistry, 18(12): 2674-2680.

Böning, P., Brumsack, H.-J., Bottcher, M.E., Schnetger, B., Kriete, C., Kallmeyer, J. and Borchers, S.V., 2004. Geochemistry of Peruvian near-surface sediments. Geochim. Cosmochim. Acta, 68(21): 4429-4451.

Böning, P., Cuypers, S., Grunwald, M., Schnetger, B., and Brumsack, H.-J. (2005) Geochemical characteristics of Chilean upwelling sediments at $\sim 36^{\circ} \mathrm{S}$. Marine Geology, 220, 1-21.

Boudreau, B. P., 1997. Diagenetic models and their implementation: Modeling transport and reactions in aquatic sediments. Springer-Verlag, Berlin Heidelberg.

Boyle, E.A., and Edmond, J.M., 1977. Determination of copper, nickel, and cadmium in sea water by APDC chelate coprecipitation and flameless atomic absorption spectrometry. Analytica Chimica Acta, 91: 189-197.

Broecker, W.S. and Peng, T.-H., 1982. Tracers in the Sea. Eldigio, Columbia Univ., New York, NY.

Calvert, S. and Pedersen, T., 1993. Geochemistry of recent oxic and anoxic marine sediments: Implications for the geological record. Marine Geology, 113: 67-88.

Chao, T.T. and Sanzolone R.F., 1992. Decomposition techniques. Journal of Geochemical Exploration, 44: 65-106.

Colodner, D., Sachs, J., Ravizza, G., Turekian, K., Edmond, J. and Boyle, E., 1993. The geochemical cycle of rhenium: a reconnaissance. Earth Planet. Sci. Lett., 117: 205221.

Crusius, J., Calvert, S. E., Pedersen T. F., Sage D., 1996. Rhenium and molybdenum enrichments in sediments as indicators of oxic, suboxic, and sulfidic conditions of deposition. Earth and Planetary Science Letters, 145: 65-78.

Crusius, J. and Thomson, J., 2003. Mobility of authigenic rhenium, silver, and selenium during postdepositional oxidation in marine sediments. Geochimica et Cosmochimica Acta, 67(2): 265-273.

Devol, A.H. and Hartnett, H.E., 2001. Role of the oxygen-deficient zone in transfer of organic carbon to the deep ocean. Limnol. Oceanogr., 46(7): 1684-1690.

Emerson, S. R. and Huested, S. S., 1991. Ocean anoxia and the concentration of molybdenum and vanadium in seawater. Marine Chemistry, 34: 177-196.

Fisher, N.S. and Wente, M., 1993. The release of trace elements by dying marine phytoplankton. Deep-Sea Res. I, 40(4): 671-694.

Flegal, A.R., Sanudo-Wilhelmy, S.A. and Scelfo, G.M., 1995. Silver in the eastern Atlantic Ocean. Marine Chem., 49: 315-320.

Friedl, G. and Pedersen, T. F., 1998. Silver as a palaeo proxy for high productivity. Mineralogical Magazine, 62A(Part I): 476-477.

Gobeil, C., Rondeau, B., and Beaudin, L., 2005. Contribution of municipal effluents to metal fluxes in the St. Lawrence River. Environ. Sci. Technol., 39: 456-464.

Hartnett, H. E., Keil, R. G., Hedges, J. I. and Devol, A. H., 1998. Influence of oxygen exposure time on organic carbon preservation in continental margin sediments. Nature, 391: 572-574. 
Hartnett, H. E. and Devol, A. H., 2003. Role of a strong oxygen-deficient zone in the preservation and degradation of organic matter: A carbon budget for the continental margins of northwest Mexico and Washington State. Geochim. Cosmochim. Acta, 67(2): 247-264.

Hedges, J.I., Hu, F.S., Devol, A.H., Hartnett, H.E., Tsamakis, E. and Keil, R.G., 1999. Sedimentary organic matter preservation: A test for selective degradation under oxic conditions. American Journal of Science, 299: 529-555.

Kalnejais, L.H., 2005. Mechanisms of Metal Release from Contaminated Coastal Sediments. Ph.D. Thesis, Massachusetts Institute of Technology/Woods Hole Oceanographic Institution, USA, 238 p.

Klein, D.A. and Mulvey, G., 1978. Amounts of silver-derived agents used in weather modification in relation to contributions from other sources. In: Klein, D.A. (Ed), Environmental impacts of artificial ice nucleating agents. Colorado State University, pp. 5-8.

Kogut, M. B. and Voelker, B. M., 2003. Kinetically inert Cu in coastal waters. Environ. Sci. Technol., 37: 509-518.

Kramer, D., 2006. An exploration of the marine silver cycle in coastal and open ocean environments of the North Pacific. MSc Thesis, University of British Columbia, Vancouver, Canada, 115 p.

Kyte, F. T., Leinen, M., Heath, G. R. and Zhou, L., 1993. Cenozoic sedimentation history of the central North Pacific: Inferences from the elemental geochemistry of core LL44-GPC3. Geochim. Cosmochim. Acta, 57: 1719-1740.

Lambourn, D., Hartnett, H., and Devol, A., 1996. Porewater data from the Washington Shelf and Slope: Cruise WE4907B of the R/V Wecoma. In: Special Report No. 113 School of Oceanography, Univ. Washington.

Lavelle, J. W., Cowen, J. P. and Massoth, G. J., 1992. A model for the deposition of hydrothermal manganese near ridge crests. Journal of Geophysical Research, 97(C5): 7413-7427.

Li, Y. and Gregory, S., 1974. Diffusion of ions in sea water and in deep-sea sediments. Geochim. Cosmochim. Acta, 38: 703-714.

Lyons, W. and Fitzgerald, W., 1983. Trace metal speciation in nearshore anoxic and suboxic porewaters. In: Wong, C., Boyle, E., Bruland, K., Burton, J., and Goldberg, E. (Eds.), Trace Metals in Seawater Marine Science Series, 9, NATO.

Martin, J. M. and Meybeck, M., 1979. Elemental mass-balance of material carried by major world rivers. Marine Chemistry, 7: 173-206.

Martin, J.H., Knauer, G.A., and Gordon, R.M., 1983. Silver distributions and fluxes in north-east Pacific waters. Nature, 305: 306-309.

McKay, J.L., Pedersen, T.F. and Mucci, A., 2007. Sedimentary redox conditions in continental margin sediments (northeastern Pacific) - Influence on the accumulation of redox - sensitive trace metals. Chemical Geology, 238(3-4): 180-196.

McKay, J.L. and Pedersen, T.F., 2002. Accumulation of redox-sensitive trace metals in continental margin sediments and their paleo-applications. Eos. Trans. AGU, 83(4), Ocean Sciences Meet. Suppl. Abstract OS32B-124.

McManus, J., Berelson, W. M., Severmann, S., Poulson, R. L., Hammond, D. E., Klinkhammer, G. P. and Holm, C., 2006. Molybdenum and uranium geochemistry in 
continental margin sediments: Paleoproxy potential. Geochim. Cosmochim. Acta, 70(18): 4643-4662.

Morford, J. and Emerson, S., 1999. Geochemistry of redox sensitive trace metals in sediments. Geochim. Cosmochim. Acta, 63(11/12): 1735-1750.

Morford, J. L., Emerson, S. R., Breckel, E. J. and Kim, S. H., 2005. Diagenesis of oxyanions $(\mathrm{V}, \mathrm{U}, \mathrm{Re}$, and $\mathrm{Mo})$ in pore waters and sediments from a continental margin. Geochimica et Cosmochimica Acta, 69: 5021-5032.

Morford, J. L., Martin, W.R., Kalnejais, L., Francois, R., Bothner, M. and Karle, I.-M., 2007. Insights on geochemical cycling of $U, R e$ and Mo from seasonal sampling in Boston Harbor, Massachusetts, U.S.A. Geochimica et Cosmochimica Acta, 71(4): 895-917.

Murray, R.W. and Leinen, M., 1993. Chemical transport to the seafloor of the equatorial Pacific Ocean across a latitudinal transect at $135^{\circ} \mathrm{W}$ : Tracking sedimentary major, minor, trace and rare earth element fluxes at the Equator and the Intertropical Convergence Zone. Geochim. Cosmochim. Acta, 57: 4141-4163.

Myers, C. R. and Nealson, K. H., 1988. Microbial reduction of manganese oxides: Interactions with iron and sulfur. Geochim. Cosmochim. Acta, 52: 2727-2732.

Nameroff, T. J., Balistrieri, L. S. and Murray J. W., 2002. Suboxic trace metal geochemistry in the eastern tropical North Pacific. Geochimica et Cosmochimica Acta, 66: 1139-1158.

Ndung'u, K., Thomas, M. and Flegal, A., 2001. Silver in the western equatorial and south Atlantic Ocean. Deep-Sea Research, Part II: Topical Studies in Oceanography, 48: 2933-2945.

Ndung'u, K., Ranville, M. A., Franks, R. P. and Flegal, A. R., 2006. On-line determination of silver in natural waters by inductively-coupled plasma mass spectrometry: Influence of organic matter. Marine Chemistry, 98: 109-120.

Nozaki, Y., 1997. A fresh look at element distribution in the North Pacific Ocean. EOS Trans. 78: 229.

Perry, M.J., Bolger, J.P. and English, D.C., 1989. Primary production in Washington coastal waters. In: Landry, M.R. and Hickey, B.M. (Eds.), Coastal Oceanography of Washington and Oregon, Elsevier, 117-173.

Ranville, M.A. and Flegal, A.R., 2005. Silver in the North Pacific Ocean. Geochemistry Geophysics Geosystems, 6(3): Q03M01, doi:10.1029/2004GC000770.

Rivera-Duarte, I. and Flegal, A.R., 1996. Microtechniques for the determination of nanomolar concentrations of trace elements in $\leq 10 \mathrm{~mL}$ of sediment porewater. Analytica Chimica Acta, 328: 13-17.

Rivera-Duarte, I. and Flegal, A.R., 1997. Pore-water silver concentration gradients and benthic fluxes from contaminated sediments of San Francisco Bay, California, U.S.A. Marine Chemistry, 56: 15-26.

Rozan, T.F. and Luther, G.W., 2002. Voltammetric evidence suggesting Ag speciation is dominated by sulfide complexation in river water. In: Taillefert, M. and Rozan, T.F., (Eds.) ACS Symposium Series: Environmental Electrochemistry: Analyses of Trace element Biogeochemistry: 371-387.

Sañudo-Wilhelmy, S.A. and Flegal, A.R., 1992. Anthropogenic silver in the southern California Bight: A new tracer of sewage in coastal waters. Environ. Sci. Technol., 26: 2147-2151.

Smith, G.J. and Flegal, A.R., 1993. Silver in San Francisco Bay Estuarine waters. Estuaries, 16(3A): 547-558. 
Stump, C. and Emerson, S., 2001. Special Report No. 117: Redox states of marine sediments from a transect along $47^{\circ} \mathrm{N}$ in the North Pacific Ocean: TTN 131 of the R/V T.G. Thompson. University of Washington, Seattle, WA.

Sung, J.F.C., Nevissi, A.E. and Dewalle, F.B., 1986. Concentration and removal efficiency of major and trace elements in municipal wastewater. J. Envion. Sci. Health, A21(5): 435-448.

Taylor, S.R. and McLennan, S.M., 1985. The Continental Crust: its Composition and Evolution: An examination of the geochemical record preserved in sedimentary rocks. Blackwell Scientific Publications.

Thamdrup, B., Fossing, H. and Jorgensen, B. B., 1994. Manganese, iron and sulfur cycling in a coastal marine sediment, Aarhus Bay, Denmark. Geochim. Cosmochim. Acta, 58(23): 5115-5129.

Turekian, K. K. and Wedepohl, K. H., 1961. Distribution of the elements in some major units of the Earth's Crust. Geological Society of America Bulletin, 72: 175-192.

Wen, L.-S., Santschi, P.H., Gill, G.A., Paternostro, C.L. and Lehman, R.D., 1997. Collodial and particulate silver in river and estuarine waters of Texas. Environ. Sci. Technol., 31: 723-731.

Yang, L. and Sturgeon, R. E., 2002. On-line determination of silver in sea-water and marine sediment by inductively coupled plasma mass spectrometry. J. Anal. At. Spectrom., 17: 88-93.

Zhang, Y., Amakawa, H. and Nozaki, Y., 2001. Oceanic profiles of dissolved silver: precise measurements in the basins of western North Pacific, Sea of Okhotsk, and the Japan Sea. Marine Chemistry, 75(1-2): 151-163.

Zheng, Y., Anderson, R. F., van Geen, A. and Kuwabara, J., 2000. Authigenic molybdenum formation in marine sediments: A link to pore water sulfide in the Santa Barbara Basin. Geochim. Cosmochim. Acta, 64(24): 4165-4178. 


\section{FIGURE CAPTIONS}

Figure 1. Map of station locations (open circles). The transect extends off the coasts of Washington and Oregon states and continues to the west side of the Juan de Fuca Ridge crest, denoted as a line between stations 5 and 6 . Literature data for surface Mn concentrations are also plotted to the south of the transect (shaded circles, data from Table 2 in Lavelle et al., 1992).

Figure 2. Pore water Fe and Mn profiles and solid phase Fe/Al and Mn/Al profiles (as mole/mole ratios) from the Washington/Oregon margin (replotted from Morford et al., 2005). The horizontal line denotes the sediment-water interface. Vertical lines on the metal/Al plots denote possible detrital values (shale: Turekian and Wedepohl, 1961; North Pacific sediment: Kyte et al., 1993; Columbia River particles: Morford and Emerson, 1999).

Figure 3. Pore water $\mathrm{Ag}$ concentrations ( $\mathrm{nmol} \mathrm{kg}_{\mathrm{pw}}{ }^{-1}$ ) of total dissolved $\mathrm{Ag}(<0.45 \mu \mathrm{m})$ from an offshore transect off the coasts of Washington/Oregon states. Note the different concentration ranges $\left(0-0.9 \mathrm{nmol} \mathrm{kg}_{\mathrm{pw}}{ }^{-1}\right.$ for stations $2,3 \mathrm{~b}$ and $4 ; 0-25$ $\mathrm{nmol} \mathrm{kg}_{\mathrm{pw}}{ }^{-1}$ for stations 5, 6, 7 and 8). Replicate measurements of station 4 pore waters were done in 2004 and 2006 and the reproducibility is within $14 \%$. The detection limit, defined as three times the standard deviation of the blank, was 4-6 pM for stations 2 and $3 \mathrm{~b}$, and 4-15 pM for stations 4, 5, 6, 7 and 8 .

Figure 4. Leached solid phase Ag concentrations ( $\mu \mathrm{mol} \mathrm{kg}_{\text {sed }}{ }^{-1}$ ) from an offshore transect off the coasts of Washington/Oregon states. Note the change in concentration range for stations 1 and 2 . 
Figure 1.

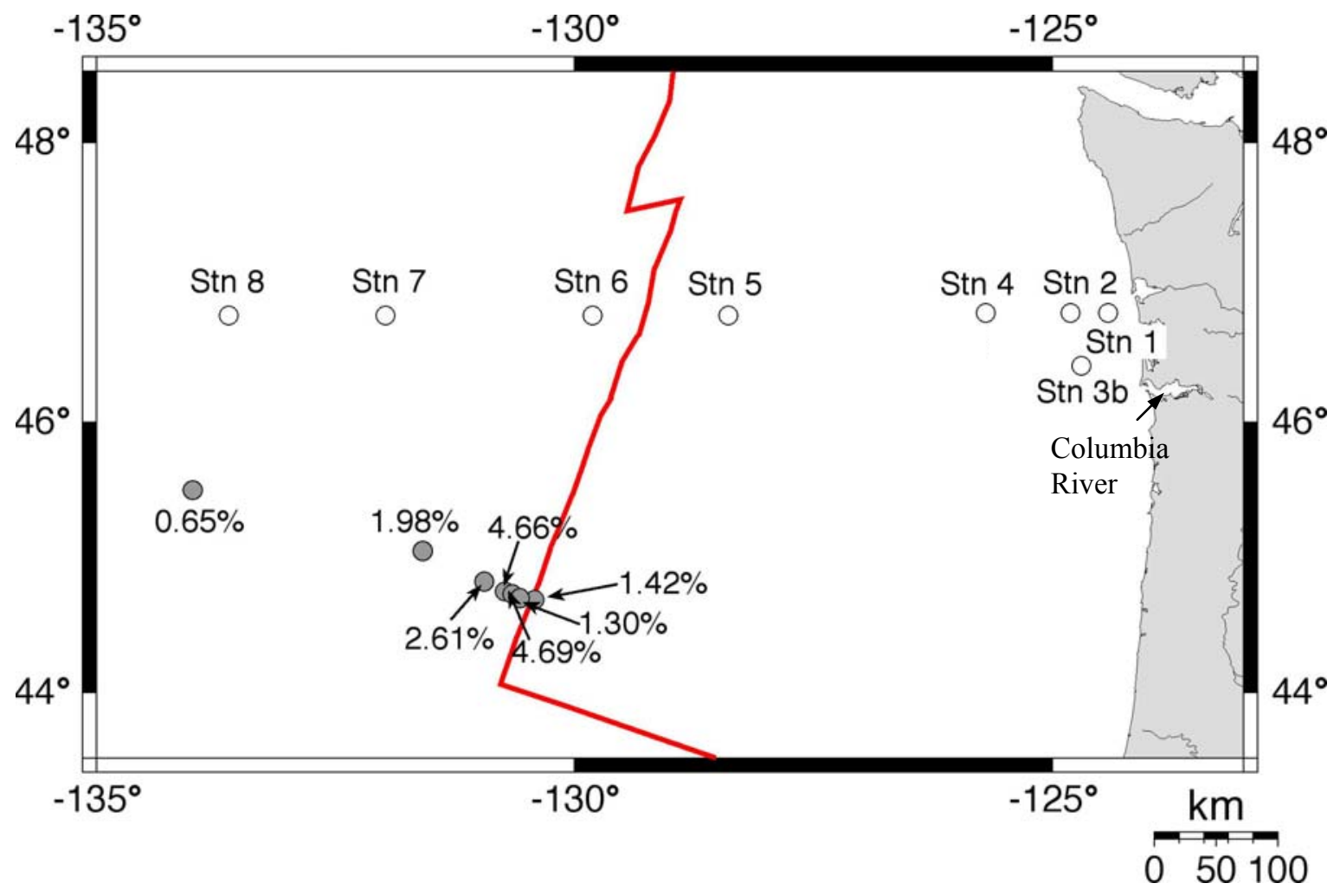


Figure 2.

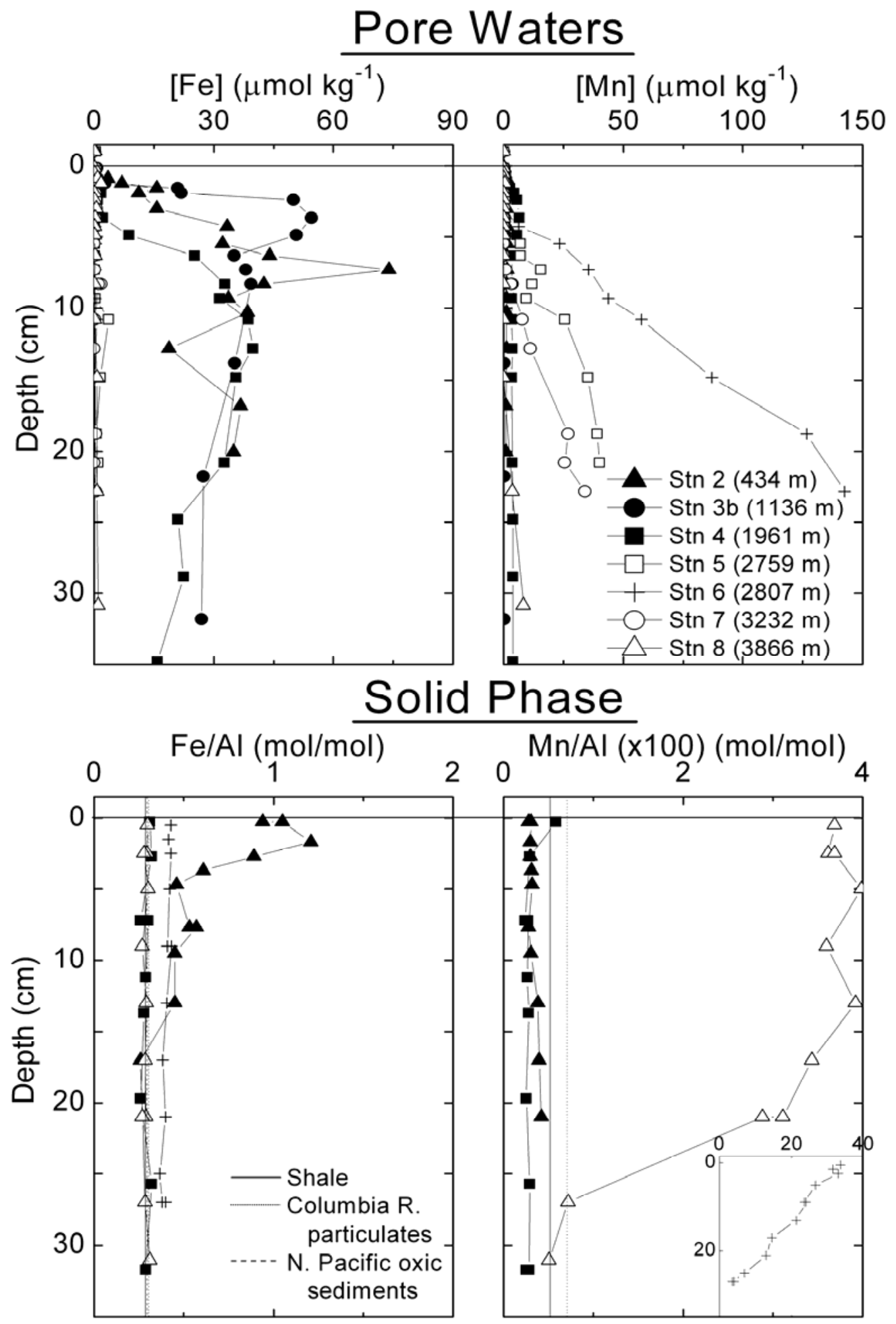


Figure 3.

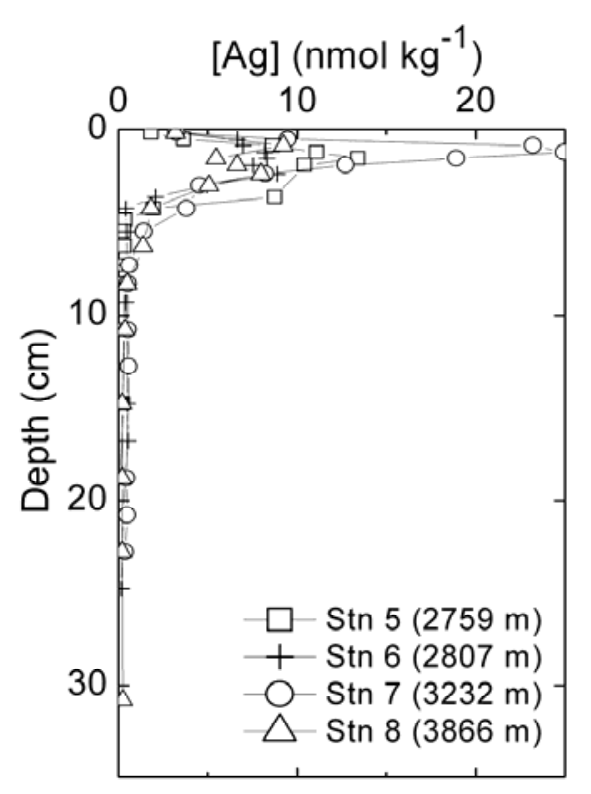

\section{Pore Waters}

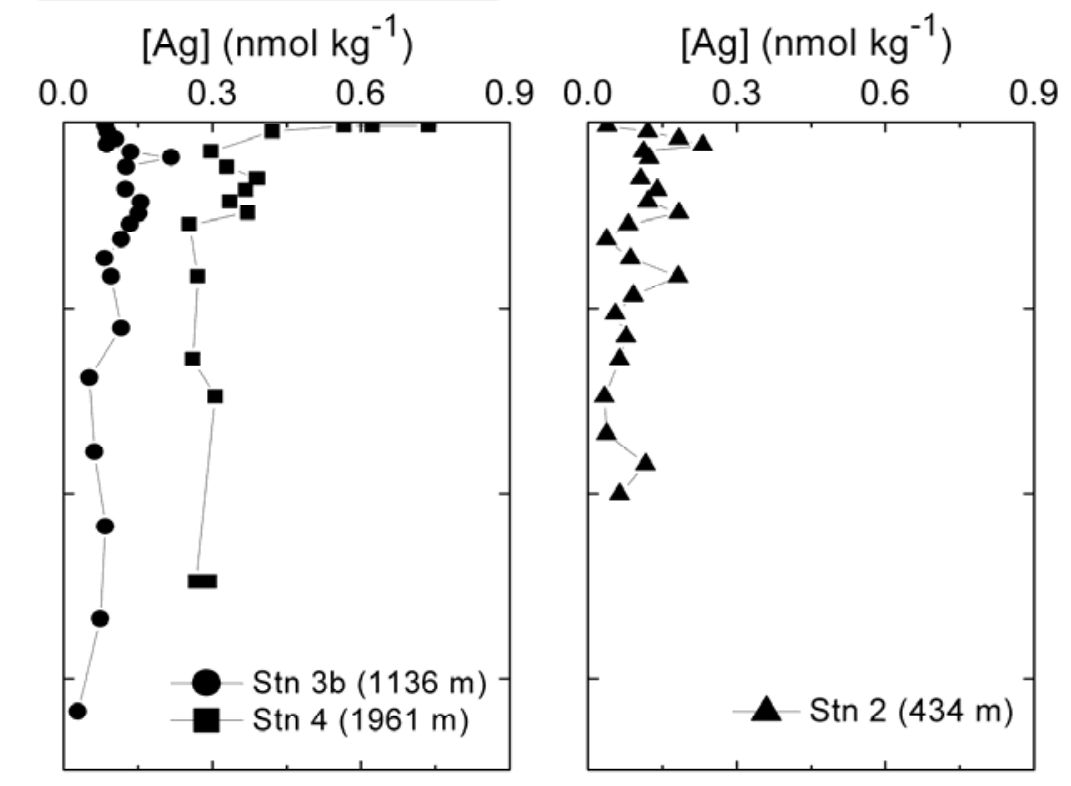


Figure 4.

\section{Solid Phase}
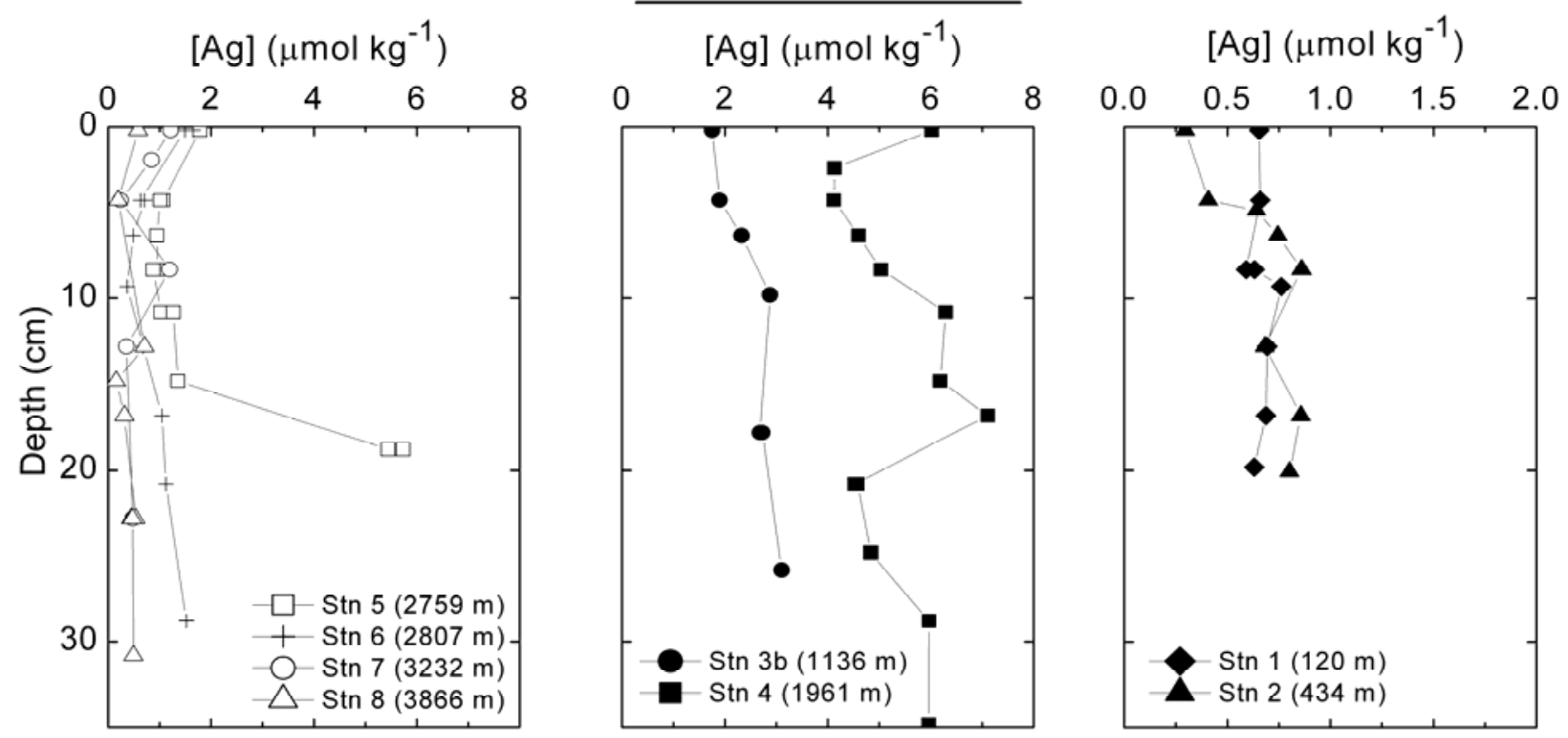
Table 1. Station information for cruise TTN-131 (July 23-August 3, 2001) (Stump and Emerson, 2001). The transect extends from $\sim 47^{\circ} \mathrm{N}$ to $\sim 133^{\circ} \mathrm{W}$ and encompasses a range of water depths. Oxygen penetration depths $\left(\mathrm{O}_{2}\right.$,pen $)$ were determined by oxygen microelectrode (Morford et al., 2005). Sedimentation rates (Sed Rate) are based on cores recovered previously from relatively close stations (Hedges et al., 1999; Lambourn et al., 1996).

\begin{tabular}{|c|c|c|c|c|c|}
\hline Station & $\begin{array}{c}\text { Lat }\left({ }^{\circ} \mathrm{N}\right), \\
\text { Long }\left({ }^{\circ} \mathrm{W}\right)\end{array}$ & $\begin{array}{c}\text { Water depth } \\
(\mathrm{m})\end{array}$ & $\begin{array}{c}{\left[\mathrm{O}_{2}\right]_{\mathrm{BW}}} \\
(\mu \mathrm{M})\end{array}$ & $\begin{array}{c}\mathrm{O}_{2, \text { pen }} \\
(\mathrm{cm})\end{array}$ & $\begin{array}{c}\text { Sed Rate } \\
\left(\mathrm{cm} \mathrm{kyr}^{-1}\right)\end{array}$ \\
\hline 1 & $46^{\circ} 46.65,124^{\circ} 35.26$ & 120 & 45 & 0.4 & $\sim 15$ \\
\hline 2 & $46^{\circ} 47.83,124^{\circ} 54.40$ & 434 & 40 & 0.3 & 15 \\
\hline $3 \mathrm{~b}$ & $46^{\circ} 25.56,124^{\circ} 41.50$ & 1136 & 14 & 0.4 & 10 \\
\hline 4 & $46^{\circ} 46.48,125^{\circ} 31.55$ & 1961 & 55 & 0.5 & 12 \\
\hline 5 & $46^{\circ} 44.98,128^{\circ} 30.01$ & 2759 & 81 & 2.5 & 2 \\
\hline 6 & $46^{\circ} 46.99,129^{\circ} 49.99$ & 2807 & 81 & 1.5 & 2 \\
\hline 7 & $46^{\circ} 47.00,132^{\circ} 00.00$ & 3232 & 115 & 1.4 & 2 \\
\hline 8 & $46^{\circ} 47.00,133^{\circ} 39.99$ & 3866 & 124 & 5.0 & 2 \\
\hline
\end{tabular}


Table 2. Range in primary productivity (Perry et al., 1989) and carbon flux to the sedimentwater interface (Devol and Hartnett, 2001) for the Washington margin.

\begin{tabular}{lcc}
\hline $\begin{array}{c}\text { Water Depth } \\
(\mathrm{m})\end{array}$ & $\begin{array}{c}\text { Primary Productivity } \\
\left(\text { mmol C m } \mathrm{d}^{-1}\right)\end{array}$ & $\begin{array}{c}\text { Carbon flux to sediment-water interface } \\
\left(\mathrm{mmol} \mathrm{C} \mathrm{m}^{-2} \mathrm{~d}^{-1}\right)\end{array}$ \\
\hline $100-200$ & $\sim 150$ & $10-20$ \\
$300-400$ & NA & $\sim 5$ \\
$200-2000$ & 70 & $\sim 1^{\mathrm{a}}$ \\
$>2000$ & 50 & NA \\
\hline
\end{tabular}

${ }^{\mathrm{a} .}$ Approximation is for $1000 \mathrm{~m}$ water depth (Devol and Hartnett, 2001). NA denotes not available. 
Table 3. Replicate analyses of CASS-4 (Nearshore Seawater Reference Material, National Research Council, Canada) and pore water samples from station 4. The measured values are reported as the average concentration \pm standard deviation with the number of individual measurements (n).

\begin{tabular}{|c|c|}
\hline Sample & Measured [Ag] (pmol kg $\left.{ }^{-1}\right)$ \\
\hline CASS- $4^{\mathrm{a}}$ & \\
\hline October $2002^{\mathrm{b}}$ & $54 \pm 6(n=5)$ \\
\hline June $2004^{c}$ & $59 \pm 10(\mathrm{n}=2)$ \\
\hline August, October $2006^{\mathrm{d}}$ & $53 \pm 3(n=15)$ \\
\hline Literature values & $57 \pm 8^{\mathrm{e}}(\mathrm{n}=7) ; 50 \pm 1^{\mathrm{f}}(\mathrm{n}=3) ; 80 \pm 20^{\mathrm{g}}(\mathrm{n}=21)$ \\
\hline $\begin{array}{l}\text { Station } 4 \text { pore waters } \\
0.12 \mathrm{~cm} \\
3.0 \mathrm{~cm} \\
24.8 \mathrm{~cm}\end{array}$ & $\begin{array}{l}0.64 \pm 0.09(n=3) \\
0.391 \pm 0.002(n=2) \\
0.28 \pm 0.02(n=2)\end{array}$ \\
\hline
\end{tabular}

\footnotetext{
${ }^{\mathrm{a}}$ The measured CASS -4 averages are separated to show accuracy and precision over the period of analysis. Although there is no certified Ag concentration for CASS-4, several literature values are available for comparison. Stations $3 b^{\mathrm{b}}, 2^{\mathrm{c}}$, and $4-8^{\mathrm{d}}$ pore waters were measured during these time periods.

'Ndung'u et al., 2001

f Yang and Sturgeon, 2002

${ }^{\mathrm{g}}$ Ndung'u et al., 2006

$\mathrm{h}$ One of each replicate pore water sample from station 4 was analyzed in 2004, while the remaining replicates were measured in 2006. The similarity in concentrations suggests a lack of storage artifacts between analyses.
} 
Table 4. Pore water silver concentrations. The depths are in units of $\mathrm{cm}$ and the Ag concentrations are in units of nmol $\mathrm{kg}^{-1}$.

\begin{tabular}{|c|c|c|c|c|c|c|c|c|c|c|c|c|c|}
\hline \multicolumn{2}{|c|}{ Station 2 (434 m) } & \multicolumn{2}{|c|}{ Station 3b (1136 m) } & \multicolumn{2}{|c|}{ Station 4 (1961 m) } & \multicolumn{2}{|c|}{ Station $5(2759 \mathrm{~m})$} & \multicolumn{2}{|c|}{ Station 6 (2807 m) } & \multicolumn{2}{|c|}{ Station 7 (3232 m) } & \multicolumn{2}{|c|}{ Station 8 (3866 m) } \\
\hline Depth & [Ag] & Depth & [Ag] & Depth & [Ag] & Depth & [Ag] & Depth & [Ag] & Depth & [Ag] & Depth & [Ag] \\
\hline 0.2 & 0.04 & 0.2 & 0.08 & 0.2 & 0.62 & 0.2 & 1.8 & 0.2 & 3.3 & 0.2 & 3.2 & 0.2 & 3.2 \\
\hline 0.5 & 0.12 & 0.5 & 0.09 & 0.2 & 0.74 & 0.5 & 3.6 & 0.5 & 6.6 & 0.5 & 9.5 & 0.9 & 9.2 \\
\hline 0.9 & 0.18 & 0.9 & 0.11 & 0.2 & 0.57 & 0.9 & 8.6 & 0.9 & 7.0 & 0.9 & 23 & 1.6 & 5.4 \\
\hline 1.2 & 0.23 & 1.2 & 0.09 & 0.5 & 0.42 & 1.2 & 11 & 1.2 & 8.2 & 1.2 & 25 & 1.9 & 6.6 \\
\hline 1.6 & 0.11 & 1.6 & 0.14 & 1.6 & 0.30 & 1.6 & 13 & 1.6 & 8.3 & 1.6 & 19 & 2.4 & 8.0 \\
\hline 1.9 & 0.12 & 1.9 & 0.22 & 2.4 & 0.33 & 1.9 & 10 & 1.9 & 7.5 & 1.9 & 13 & 3.0 & 5.1 \\
\hline 3.0 & 0.11 & 2.4 & 0.13 & 3.0 & 0.39 & 3.6 & 8.8 & 2.4 & 8.9 & 2.4 & 8.2 & 4.3 & 1.8 \\
\hline 3.6 & 0.14 & 3.6 & 0.13 & 3.0 & 0.39 & 4.3 & 1.9 & 3.0 & 5.0 & 3.0 & 4.6 & 6.3 & 1.4 \\
\hline 4.3 & 0.12 & 4.3 & 0.16 & 3.6 & 0.37 & 4.9 & 0.35 & 3.6 & 2.1 & 4.3 & 3.8 & 8.3 & 0.50 \\
\hline 4.9 & 0.18 & 4.9 & 0.15 & 4.3 & 0.34 & 5.5 & 0.30 & 4.3 & 0.41 & 5.5 & 1.4 & 10.8 & 0.35 \\
\hline 5.5 & 0.08 & 5.5 & 0.13 & 4.9 & 0.37 & 6.3 & 0.34 & 5.5 & 0.46 & 7.3 & 0.60 & 14.8 & 0.20 \\
\hline 6.3 & 0.04 & 6.3 & 0.12 & 5.5 & 0.25 & 7.3 & 0.32 & 7.3 & 0.44 & 8.3 & 0.54 & 18.8 & 0.22 \\
\hline 7.3 & 0.09 & 7.3 & 0.08 & 8.3 & 0.27 & 8.3 & 0.34 & 9.3 & 0.40 & 10.8 & 0.53 & 22.8 & 0.22 \\
\hline 8.3 & 0.18 & 8.3 & 0.10 & 12.8 & 0.26 & 10.8 & 0.29 & 10.8 & 0.47 & 12.8 & 0.55 & 30.8 & 0.25 \\
\hline 9.3 & 0.09 & 11.1 & 0.12 & 14.8 & 0.31 & 14.8 & 0.26 & 14.8 & 0.50 & 18.8 & 0.45 & & \\
\hline 10.3 & 0.06 & 13.8 & 0.05 & 24.8 & 0.27 & 18.8 & 0.11 & 16.8 & 0.51 & 20.8 & 0.49 & & \\
\hline 11.6 & 0.08 & 17.8 & 0.06 & 24.8 & 0.30 & & & 20.8 & 0.24 & 22.8 & 0.38 & & \\
\hline 12.8 & 0.06 & 21.8 & 0.08 & & & & & 24.8 & 0.18 & & & & \\
\hline 14.8 & 0.03 & 26.8 & 0.08 & & & & & & & & & & \\
\hline 16.8 & 0.04 & 31.8 & 0.03 & & & & & & & & & & \\
\hline 18.4 & 0.12 & 35.8 & 0.08 & & & & & & & & & & \\
\hline 20.1 & 0.06 & & & & & & & & & & & & \\
\hline
\end{tabular}


Table 5. Replicate analyses of PACS-2 and MESS-3 (Marine sediment reference material, National Research Council Canada) determined by the leach and total dissolution methods. The measured values are reported as the average concentration \pm standard deviation with the number of individual measurements (n). The known concentrations, which are only for complete dissolution, are reported with their standard deviations at the $95 \%$ confidence limits.

\begin{tabular}{|l|l|l|}
\hline Standard & $\begin{array}{l}{[\text { Ag] }} \\
\left(\mu \mathrm{mol} \mathrm{kg}{ }^{-1} \text { dry sediment }\right)\end{array}$ & $\begin{array}{l}\text { Certified [Ag] } \\
\left(\mu \mathrm{mol} \mathrm{kg}^{-1} \text { dry sediment }\right)\end{array}$ \\
\hline $\begin{array}{l}\text { PACS-2 } \\
\text { Leach method }\end{array}$ & \\
Total dissolution method & $\begin{array}{l}10.9 \pm 0.8(\mathrm{n}=21) \\
13 \pm 4(\mathrm{n}=2)\end{array}$ & $11.3 \pm 1.3$ \\
\hline $\begin{array}{l}\text { MESS-3 } \\
\text { Leach method }\end{array}$ & $1.5 \pm 0.1(\mathrm{n}=29)$ & \\
Total dissolution method & $2.0 \pm 0.1(\mathrm{n}=5)$ & $1.67 \pm 0.18$ \\
\hline
\end{tabular}


Table 6. Solid phase non-lithogenic silver concentrations as determined using the leach method described in the text. The depths are in units of $\mathrm{cm}$ and the $\mathrm{Ag}$ concentrations are in units of $\left(\mu \mathrm{mol} \mathrm{kg}{ }^{-1}\right)$. Concentrations in parentheses were determined using the total dissolution method. The difference between the total dissolution method concentration and the leach method concentration approximates the refractory $\mathrm{Ag}$ concentration.

\begin{tabular}{|c|c|c|c|c|c|c|c|c|c|c|c|c|c|c|c|}
\hline \multicolumn{2}{|c|}{$\begin{array}{l}\text { Station } 1 \\
(120 \mathrm{~m})\end{array}$} & \multicolumn{2}{|c|}{$\begin{array}{l}\text { Station } 2 \\
(434 \mathrm{~m}) \\
\end{array}$} & \multicolumn{2}{|c|}{$\begin{array}{l}\text { Station 3b } \\
(1136 \mathrm{~m})\end{array}$} & \multicolumn{2}{|l|}{$\begin{array}{l}\text { Station } 4 \\
(1961 \mathrm{~m})\end{array}$} & \multicolumn{2}{|c|}{$\begin{array}{l}\text { Station } 5 \\
(2759 \mathrm{~cm})\end{array}$} & \multicolumn{2}{|c|}{$\begin{array}{c}\text { Station } 6 \\
(2807 \text { m) }\end{array}$} & \multicolumn{2}{|c|}{$\begin{array}{l}\text { Station } 7 \\
\text { (3232 m) }\end{array}$} & \multicolumn{2}{|c|}{$\begin{array}{l}\text { Station } 8 \\
(3866 \mathrm{~m}) \\
\end{array}$} \\
\hline Depth & [Ag] & Depth & [Ag] & Depth & [Ag] & Depth & [Ag] & Depth & [Ag] & Depth & [Ag] & Depth & [Ag] & Depth & [Ag] \\
\hline 0.2 & 0.66 & 0.2 & $\begin{array}{r}0.30 \\
(0.50)\end{array}$ & 0.2 & $\begin{array}{r}1.8 \\
(3.3)\end{array}$ & 0.2 & 6.0 & 0.2 & 1.8 & 0.2 & 1.6 & 0.2 & 1.2 & 0.2 & 0.58 \\
\hline 4.3 & 0.66 & 4.3 & 0.41 & 4.3 & 1.9 & 2.4 & 4.1 & 4.3 & 1.1 & 0.2 & 1.5 & 1.9 & 0.85 & 4.3 & 0.19 \\
\hline 8.3 & $\begin{array}{r}0.59 \\
(0.96) \\
\end{array}$ & 4.9 & 0.64 & 6.3 & 2.3 & 4.3 & 4.1 & 4.3 & 1.0 & 4.3 & $\begin{array}{c}0.63 \\
(0.83) \\
\end{array}$ & 4.3 & $\begin{array}{c}0.24 \\
(0.52) \\
\end{array}$ & 12.8 & 0.71 \\
\hline 8.3 & 0.63 & 6.3 & 0.74 & 9.8 & 2.9 & 6.3 & 4.6 & 6.3 & 1.0 & 4.3 & 0.71 & 8.3 & 1.2 & 14.8 & 0.16 \\
\hline 9.3 & 0.76 & 8.3 & $\begin{array}{r}0.86 \\
(1.1) \\
\end{array}$ & 17.8 & $\begin{array}{r}2.7 \\
(3.9) \\
\end{array}$ & 8.3 & 5.0 & 8.3 & $\begin{array}{c}1.0 \\
(1.4) \\
\end{array}$ & 6.3 & 0.48 & 12.8 & 0.36 & 16.8 & 0.32 \\
\hline 12.8 & 0.69 & 8.3 & 0.86 & 17.8 & 2.7 & 10.8 & 6.3 & 8.3 & 0.88 & 9.3 & 0.37 & 22.8 & $\begin{array}{c}0.48 \\
(0.65) \\
\end{array}$ & 22.8 & 0.53 \\
\hline 16.8 & 0.69 & 12.8 & 0.68 & 25.8 & 3.1 & 14.8 & 6.2 & 10.8 & 1.0 & 12.8 & 0.68 & & & 22.8 & 0.45 \\
\hline 19.8 & $\begin{array}{r}0.63 \\
(1.0) \\
\end{array}$ & 16.8 & 0.86 & & & 16.8 & 7.1 & 10.8 & 1.3 & 16.8 & 1.0 & & & 22.8 & 0.48 \\
\hline & & 20.1 & $\begin{array}{r}0.80 \\
(1.4) \\
\end{array}$ & & & 20.8 & $\begin{array}{r}4.5 \\
(5.5) \\
\end{array}$ & 14.8 & 1.4 & 20.8 & 1.1 & & & 30.8 & 0.49 \\
\hline & & & & & & 20.8 & 4.6 & 18.8 & 5.4 & 28.8 & $\begin{array}{c}1.5 \\
(2.0)\end{array}$ & & & & \\
\hline & & & & & & 24.8 & $\begin{array}{r}4.8 \\
(5.3) \\
\end{array}$ & 18.8 & $\begin{array}{r}5.7 \\
(6.6) \\
\end{array}$ & & & & & & \\
\hline & & & & & & 24.8 & 4.8 & & & & & & & & \\
\hline & & & & & & 28.8 & 6.0 & & & & & & & & \\
\hline & & & & & & 34.8 & 6.0 & & & & & & & & \\
\hline
\end{tabular}


Table 7. Silver concentrations for sedimentary shale (Turekian and Wedepohl, 1961), upper continental crust (Taylor and McLennan, 1985), and the refractory Ag concentration for the Washington/Oregon margin samples at stations 1,2, 4, 5, 6 and 7 based on the average difference between the total dissolution concentrations and the leached Ag concentrations. Results from station $3 \mathrm{~b}$ have been omitted due to additional input via the Columbia River.

\begin{tabular}{|c|c|}
\hline Sample Type & [Ag] $\left(\mu \mathrm{mol} \mathrm{kg} \mathbf{~}^{-1}\right)$ \\
\hline Shale (Turekian and Wedepohl, 1961) & 0.65 \\
\hline Upper continental crust (Taylor and McLennan, 1985) & 0.46 \\
\hline Refractory Ag as the average (total $[\mathrm{Ag}]-$ leach $[\mathrm{Ag}]$ ) & $0.4 \pm 0.3(n=13)$ \\
\hline
\end{tabular}


Table 8. Upward and downward Ag fluxes are calculated from pore water gradients at stations 2, 3b, 4, 5, 6, 7 and 8, with depth ranges used in the flux determinations in parentheses below the gradients.

\begin{tabular}{|c|c|c|c|c|c|c|c|c|}
\hline & \multicolumn{3}{|c|}{ UPWARD FLUXES $^{\mathrm{a}}$} & \multicolumn{5}{|c|}{ DOWNWARD FLUXES } \\
\hline Stn & $\frac{\Delta[\mathrm{Ag}]^{\mathrm{C}}}{\Delta \mathrm{z}}$ & Porosity $^{d}$ & Flux & $\frac{\Delta[\mathbf{A g}]^{\mathrm{C}}}{\Delta \mathrm{z}}$ & Porosity $^{d}$ & Flux $_{\text {down }}^{e}$ & $\begin{array}{l}\text { Calculated } \\
{[\text { Ag }]_{\text {solid }}}\end{array}$ & $\begin{array}{l}\text { Measured } \\
{[A g]_{\text {solid }} \text { g }}\end{array}$ \\
\hline 2 & $\begin{array}{l}0.10 \\
(0-0.2 \mathrm{~cm})\end{array}$ & 0.75 & 0.02 & $\begin{array}{l}-0.0074 \\
\quad(3.6-11.6 \mathrm{~cm})\end{array}$ & 0.65 & -0.0007 & 0.05 & 0.78 \\
\hline $3 b$ & $\begin{array}{l}0.30 \\
(0-0.2 \mathrm{~cm})\end{array}$ & 0.93 & 0.07 & $\begin{array}{l}-0.018 \\
\quad(4.3-8.3 \mathrm{~cm})\end{array}$ & 0.88 & -0.004 & 1 & 2.9 \\
\hline 4 & $\begin{array}{l}3.2 \\
(0-0.2 \mathrm{~cm})\end{array}$ & 0.94 & 0.8 & $\begin{array}{l}-0.042 \\
\quad(3.0-5.5 \mathrm{~cm})\end{array}$ & 0.85 & -0.008 & 2 & 5.8 \\
\hline 5 & $\begin{array}{l}8.8 \\
(0.2-1.6 \mathrm{~cm})\end{array}$ & 0.92 & 2 & $\begin{array}{l}-3.4 \\
(1.6-4.3 \mathrm{~cm})\end{array}$ & 0.90 & -0.7 & 1,000 & 2.7 \\
\hline 6 & $\begin{array}{l}3.3 \\
(0.2-1.6 \mathrm{~cm}) \\
\end{array}$ & 0.92 & 0.7 & $\begin{array}{l}-4.6 \\
(2.4-4.3 \mathrm{~cm}) \\
\end{array}$ & 0.90 & -1 & 2,000 & 1.1 \\
\hline 7 & $\begin{array}{l}23 \\
(0.2-1.2 \mathrm{~cm})\end{array}$ & 0.91 & 5 & $\begin{array}{r}-11 \\
\quad(1.2-3.0 \mathrm{~cm})\end{array}$ & 0.89 & -2 & 4,000 & 0.42 \\
\hline 8 & $\begin{array}{l}1.3 \\
(0.2-2.41 \mathrm{~cm})\end{array}$ & 0.85 & 0.2 & $\begin{array}{l}-1.1 \\
\quad(2.4-8.3 \mathrm{~cm})\end{array}$ & 0.80 & -0.2 & 200 & 0.43 \\
\hline
\end{tabular}

${ }^{\mathrm{a}}$ The more conservative calculation of the upward flux is calculated when the depth range is within the profile. When the depth range starts at 0 , then the concentration difference includes an estimate of the bottom water $\mathrm{Ag}$ concentration for that water depth (Kramer, 2002).

${ }^{\mathrm{b}}$ The downward flux is the flux of Ag into sediments and is negative due to the slope in the Ag profile.

${ }^{\mathrm{c}}$ Gradients are in units of $\mathrm{nmol} \mathrm{kg}{ }^{-1} \mathrm{~cm}^{-1}$.

${ }^{\mathrm{d}}$ Porosity is in units of $\mathrm{cm}_{\mathrm{w}}^{3} \mathrm{~cm}^{-3}{ }_{\mathrm{s}}$ (Stump and Emerson, 2001).

${ }^{e}$ The diffusive fluxes (nmol cm ${ }^{-2} \mathrm{y}^{-1}$ ) are calculated as $\mathrm{F}=\phi \mathrm{D}_{\mathrm{sed}} \frac{\mathrm{d}[\mathrm{Ag}]}{\mathrm{dz}}$ over the depth range indicated in parentheses.

The diffusion coefficient at infinite dilution was taken from Boudreau (1997) and Li and Gregory (1974) and corrected for in situ bottom water temperature (Stump and Emerson, 2001). The diffusion coefficient in sediments $\left(D_{\text {sed }}\right)$ is calculated as ${ }_{D_{\text {sed }}}=\frac{D_{\text {sw }}^{o}}{\theta^{2}}$ using $\theta^{2}=1-\ln \left(\phi^{2}\right)$ to determine the tortuosity factor, where $\phi$ is porosity (Stump and Emerson, 2001).

${ }^{\mathrm{f}}$ The solid phase Ag concentration in sediments $\left(\mu \mathrm{mol} \mathrm{kg}{ }_{\mathrm{s}}^{-1}\right)$ is calculated assuming that the $\mathrm{F}_{\text {downward }}=\mathrm{F}_{\text {solidphase }}$ or $\phi \mathrm{D}_{\text {sed }} \frac{\mathrm{d}[\mathrm{Ag}]_{\mathrm{pw}}}{\mathrm{dz}}=\omega(1-\phi) \mathrm{\rho}_{\mathrm{s}}[\mathrm{Ag}]_{\mathrm{solid}}$. The sedimentation rate $(\omega)$ is from Table 1 and the sediment density $\left(\rho_{\mathrm{s}}\right)$ is assumed to be $2.65 \mathrm{~g} \mathrm{~cm}^{-3}$.

${ }^{\mathrm{g}}$ The measured $\mathrm{Ag}$ concentrations $\left(\mu \mathrm{mol} \mathrm{kg}{ }_{\mathrm{s}}^{-1}\right.$ ) are the average $\mathrm{Ag}$ concentrations from the leach method below 10 $\mathrm{cm}$. 